\title{
The effect of the prismatic filler arrangement and cross-sectional shape on the thermal conductivity of polymer composites
}

\author{
X. J. Wang* \\ School of Chemistry and Biological Engineering, Lanzhou Jiaotong University, Lanzhou, Gansu 730070, China
}

Received 13 May 2014; accepted in revised form 3 July 2014

\begin{abstract}
Incorporation of fillers with high thermal conductivity to base materials has been recognized as an efficient way to increase the thermal conductivity of composite materials. In this study, the effects of the prismatic filler arrangement and cross-sectional shape on the thermal conductivity of the composites were investigated. This research addresses these problems by solving the heterogeneous two-dimensional heat conduction problem in the composite materials. A validated commercial software-FLUENT and finite volume method was used in the analysis. The close-packed, directional and random filler arrangements were considered. It was found that the prismatic filler arrangement and cross-sectional shape have great impacts on the thermal conductivity of the composite materials. Double Y shaped, I shaped, T shaped, elliptical, rhombic and rectangular cross-sectional fillers can greatly increase the thermal conductivity only in directional arrangement. The effects of circular, square, triangular and Y shaped cross-sectional are similar in directional and random arrangements. The close-packed arrangements for all cross-sectional shapes have small thermal conductivity. The double Y shaped, Y shaped and I shaped cross-sectional were found to be the best choice for composite materials regardless of the filler arrangements.
\end{abstract}

Keywords: polymer composites, thermal conductivity, directional arrangement, close-packed arrangement, filler shapes

\section{Introduction}

Thermal management devices such as heat exchangers and heat sinks are the key equipments in various industries like air-conditioning, refrigeration, energyrecovery, electronic communication and so on [1-3]. The performance of a heat exchanger is often important to the overall efficiency, cost and size of the system. Conventional heat exchangers are mainly made of monolithic metals and metal alloys. Metals are applied extensively. Regretfully, metallic heat exchangers cannot operate at acid environments for extended periods of time, and the thermal shock shortens their operation life [4]. To solve this problem, plastics or polymers instead of metals have been used to make heat exchangers [5-7]. However, the thermal conductivity of polymers is very low, that makes the overall heat transfer coefficients of plastic heat exchangers very low. The consequence is that a larger heat transfer area is required to offset this shortcoming, which makes the polymer heat exchanger very bulky [8].

It has been recognized that adding fillers of high conductivity to the base polymers is an efficient method to increase the thermal conductivity of the base polymer. Many kinds of thermal conductive fillers are introduced into the composites, such as alumina, aluminum nitride, boron nitride, graphite and carbon nanotube [9-11]. In this way, thermal conductivity of polymers is increased while their virtue can be largely kept.

The filler content and its thermal conductivity were reported to be the two dominant factors influencing

\footnotetext{
${ }^{*}$ Corresponding author, e-mail: xjwang@mail.lzjtu.cn

(C) BME-PT
} 
the overall thermal conductivity of polymer composites. Previous work and various correlations were mainly focused on these two respects [12-24]. These studies only considered simple filler shapes with uniform filler arrangement [25-29]. Relatively little attention has been paid to the effects of other typical filler arrangements and filler shapes. It is believed that the thermal conductivity of the composite materials is not a simple mixing between the fillers and base materials. Rather, filler's arrangement and shape would have great impacts on the final thermal conductivity of composite materials. The effects of three typical prismatic filler arrangements and ten filler cross-sectional shapes would be investigated in this study. A representing micro cell comprising of fillers and a base material was selected. The heat transfer between fillers and the base materials was modeled by a two-dimensional heat conduction model. Then it was used to reflect the effects of prismatic filler arrangements and cross-sectional shapes. This is the novelty of this study.

\section{Numerical work}

\subsection{Generation of unit cell model}

To make the calculation of numerical models easy, a two-dimensional elementary cell comprising of fillers in the base polymer material is considered. The cell is small and convenient for calculations, but large enough to represent a periodic section in the material. The fillers are arranged in the base materials with no contact each other. This is true when the filler content is below $20 \%$. When the fillers are contacting together, the mechanical strength of the composite materials will be seriously deteriorated [30]. The effect of interfacial thermal resistance is very inconspicuous, when filler size greater than $1 \mu \mathrm{m}$. At room temperatures, its effect is very small, and the particle size will have to be in the nanoscale range for the effect to be significant [39]. We discuss the effects of macroscopic filler shapes and arrangements, and the interfacial thermal resistance between fillers and matrix can be ignored in this study. The areas of cross-sections of fillers studied are around $0.25 \mathrm{~mm}^{2}$ each. The cell selected here is a $1 \times 1 \mathrm{~cm}^{2}$ and has a dozen of fillers, represents a periodic section in the composite material. The fillers may have different shapes and orientation angles on the two-dimensional surface. Table 1 lists ten crosssectional shapes of the fillers considered in this study: circular, square, equilateral triangular, rhombic, elliptical, rectangular, T shaped, I shaped, Y shaped and double Y shaped. They are artificially designed, to evaluate the effects of filler arrangement and filler shape. They can be orient freely on the $x-y$ plane (Figure 1). In the table, their orientation angles are defined as $0^{\circ}$ when the filler cross-sectional main axis (the vertical axis) overlaps with the heat flux direction.

Three typical filler arrangements are considered in this study. (1) Close-packed arrangement, in which all the fillers are close-packed in the central of polymer matrix with $0^{\circ}$ orientation angle. It is similar to the filler clusters, increasing heat transfer by the combined effects of all fillers. These clusters are usually observed in composites with inadequate treatment. (2) Directional arrangement, all the fillers cross-sectional mains axes are randomly located parallel to the heat flux direction. The positions of filler cross-sections are randomly assigned, however the orientation angles are equaled to $0^{\circ}$. At present, many new processing technologies are used to improve performance of composites by controlling the orientation angle of fillers [31]. (3) Random arrangement, the position and orientation angle are randomly assigned in the cell. This is in agreement with practical composite materials. The fillers are mixed with the base material completely, so they are randomly distributed.

Figure 1 demonstrates the case that there is one filler in base materials. Its position and orientation angle can be specified by its coordinates $\left(x_{0}, y_{0}\right)$ at the filler cross-sectional center and the orientation angle $\left(\beta_{0}\right)$ between its cross-sectional main axis and the heat flux direction $y$.

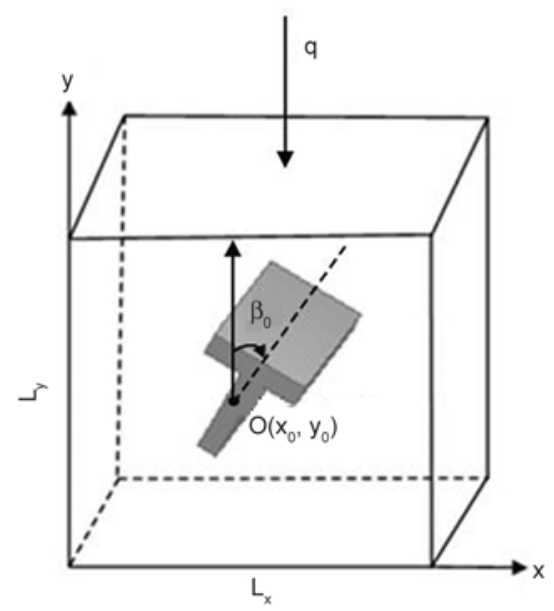

Figure 1. Schematic of a filler arranged in base materials 
Table 1. The cross-sectional shapes of fillers and their parameters

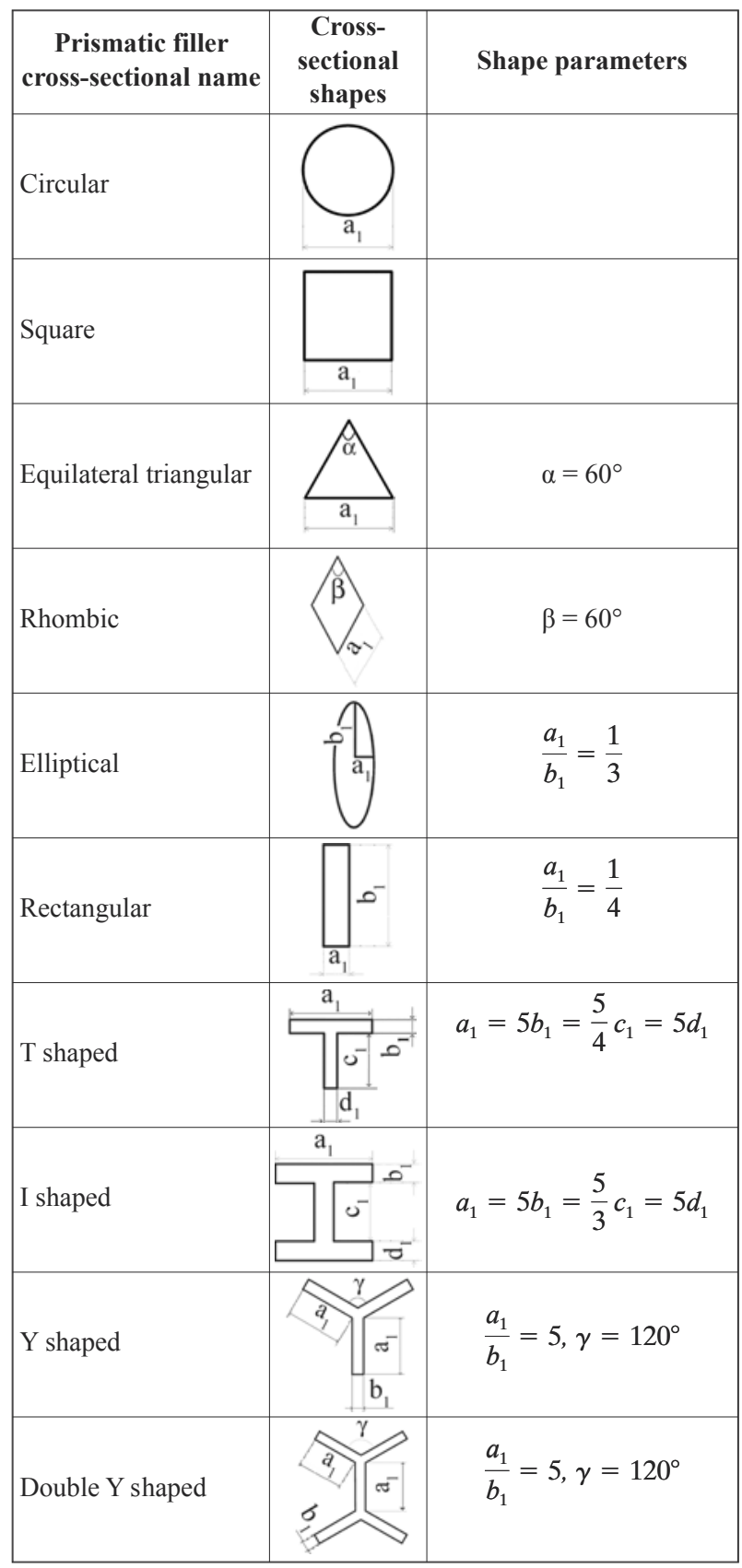

A computer program is developed to automatically generate the positions and orientation angles of fillers [32-34]. At first, the positions for the filler cross-sectional centers are determined. Let coordinates $\left(x_{0}, y_{0}\right)$ represent the positions of filler crosssectional centers. Let $L_{\mathrm{x}}$ and $L_{\mathrm{y}}$ denote the length and height of the unit cell respectively, as shown in Figure 1 . Then a random number $r_{\mathrm{X}}\left(0<r_{\mathrm{x}}<1\right)$ is generated by the computer. The coordinate $x_{0}$ is selected as the product of $r_{\mathrm{x}}$ and $L_{\mathrm{x}}$. In a similar way coordinate $y_{0}$ is obtained. At last, the orientation angles of the filler cross-sections are assigned. If the filler arrangement type is directional arrangement, the main axes of the filler cross-sections are set parallel to heat flux direction and the orientation angels are $0^{\circ}$. If it is random arrangement, the orientation angle $\beta_{0}$, defined as the angle between the filler cross-sectional main axis and the heat flux direction, is decided as the product of $2 \pi$ and a random number from 0 to 1 . In the process of the filler generation, if new filler is found to overlap with any other old fillers or boundaries, it is cancelled and new one is generated. The filler generation process ends when desired filler content is reached. The geometric models generated by the computer with directionally and randomly assigned fillers are shown in Figure $2 b$ and $2 c$. The filler cross-sectional shape is I shaped and the filler content is $9 \%$. As a comparison, the closepacked cell is artificial generation in Figure 2a. The nearest distance between the adjacent fillers is $0.05 \mathrm{~mm}$. It is very similar to the cluster formation of the fillers.

In order to reflect the overall performance of the composites with different filler arrangements, a minimum number of fillers must be included in the model. If the number of fillers is too small, the results of different generations may be somewhat different. Consequently, the size of model must be chosen to be large enough to contain the minimum number of fillers, as long as computer capacity permits.

Figure 3 presents the effects of computational model sizes on the relative thermal conductivity of composite. As seen, when the model size becomes larger than $0.3 \mathrm{~cm}^{2}$, the thermal conductivity is stable and the fluctuations from generation of cell is lower than $2 \%$, regardless of the filler arrangement and content. The differences of thermal conductivity in $x$-and $y$ - directions are within $2 \%$ for randomly arranged cell. The cell selected here is a $1 \times 1 \mathrm{~cm}^{2}$ square. It is large enough for this two-dimensional thermal conductivity calculation.

\subsection{Heat conduction equations}

For the two-dimensional cell generated in Figure 2, heat conduction in base materials is satisfied by Equation (1):

$\frac{K_{\mathrm{m}}}{\left(\rho c_{\mathrm{p}}\right)_{\mathrm{m}}}\left(\frac{\partial^{2} T_{\mathrm{m}}}{\partial x^{2}}+\frac{\partial^{2} T_{\mathrm{m}}}{\partial y^{2}}\right)=0$

where, $T$ is temperature and $x, y$ are coordinates, subscript ' $m$ ' means base polymer materials. The physical properties, heat conductivity $K$, density $\rho$ and 

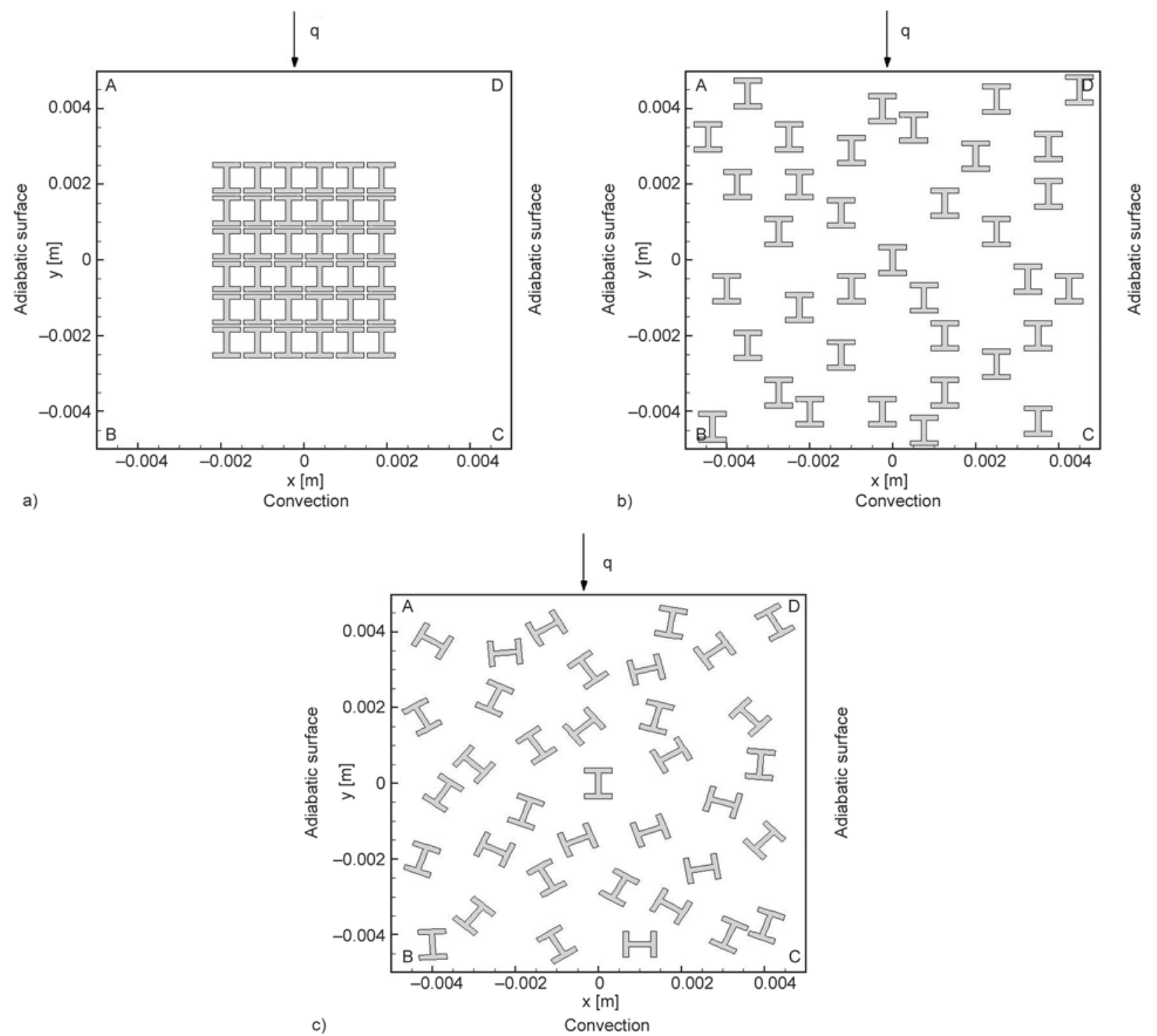

Figure 2. Two-dimensional cell model comprising of I shaped cross-sectional fillers and the base material, $V_{\mathrm{f}}=0.09$. (a) close-packed arrangement, (b) directional arrangement, (c) random arrangement.

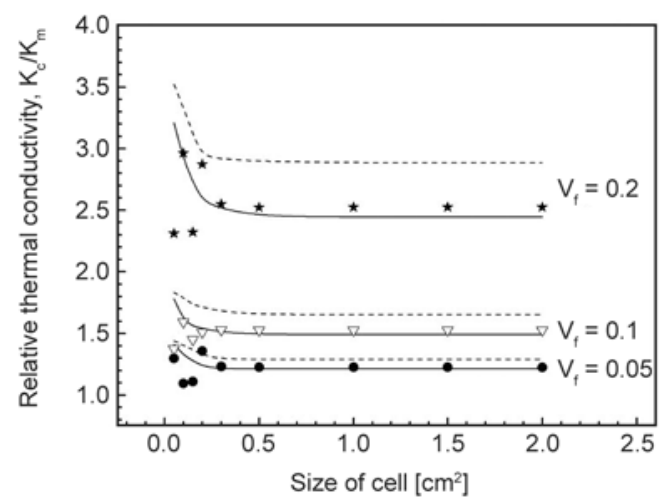

Figure 3. Effects of cell size on the relative thermal conductivity of composite, $K_{\mathrm{m}}=0.36 \mathrm{~W} \cdot \mathrm{m}^{-1} \cdot \mathrm{K}^{-1}, K_{\mathrm{f}}=$ $50.2 \mathrm{~W} \cdot \mathrm{m}^{-1} \cdot \mathrm{K}^{-1}$. Solid lines represent the data in close-packed arrangement. Dash lines represent the data in directional arrangement. The discrete points are the value in random arrangement. specific heat $c_{\mathrm{p}}$ here are written out, to reflect the local properties of the grids.

Heat conduction in the filler is described by Equation (2):

$\frac{K_{\mathrm{f}}}{\left(\rho c_{\mathrm{p}}\right)_{\mathrm{f}}}\left(\frac{\partial^{2} T_{\mathrm{f}}}{\partial x^{2}}+\frac{\partial^{2} T_{\mathrm{f}}}{\partial y^{2}}\right)=0$

The boundary condition at the top surface of the cell, AD is given by Equation (3):

$$
-\left.K_{\mathrm{m}} \frac{\partial T}{\partial n}\right|_{\mathrm{r}}=q
$$

where, $q$ is the heat flux, which is uniformly imposed on the upper surface, $n$ is the normal direction of the surface. It is the second class boundary condition. In calculation, $q$ is set to $1 \mathrm{~kW} / \mathrm{m}^{2}$. 
A third class boundary condition is set on the bottom surface of the cell, BC as shown by Equation (4):

$\left.K_{\mathrm{m}} \frac{\partial T}{\partial n}\right|_{\mathrm{r}}=h\left(T-T_{\mathrm{f}}\right)_{\mathrm{r}}$

where, the convective heat transfer coefficient $(h)$ and ambient temperature $\left(T_{\mathrm{f}}\right)$ are set to constants. In this work, $h$ is set to $20 \mathrm{~W} \cdot \mathrm{m}^{-2} \cdot \mathrm{K}^{-1}$, and $T_{\mathrm{f}}$ is set to $300 \mathrm{~K}$. The heat flows through the cell is prescribed and known as $q$, but the temperatures on other boundaries are unknown. They should be calculated by the heat conduction equations with the boundary conditions.

The other two boundary conditions, $\mathrm{AB}, \mathrm{DC}$ is given by Equation (5):

$$
\left.\frac{\partial T}{\partial n}\right|_{\mathrm{r}}=0
$$

\subsection{Heat conduction coupling}

At the boundaries between the base materials and the fillers, the temperatures in the base materials are equaled to the fillers. They are expressed as Equation (6):

$T_{\mathrm{m} \text {, interface }}=T_{\mathrm{f}, \text { interface }}$

where, subscript 'interface' means contact surfaces between the base materials and the fillers.

When the temperature fields in the cell are calculated, the thermal conductivity in $y$ direction for the cell is estimated by Equation (7):

$K_{\mathrm{c}}=\frac{q L_{\mathrm{y}}}{T_{\mathrm{t}}-T_{\mathrm{b}}}$

where, $T_{\mathrm{t}}-T_{\mathrm{b}}$ is the mean temperature difference between the upper and bottom surfaces of the cell. The surface mean temperature here is weighted by area $L_{\mathrm{x}}$. Dimensions $L_{\mathrm{x}}$ (along the $x$ axis) and $L_{\mathrm{y}}$ (along the $y$ axis) are the cell length and height.

\subsection{Calculation scheme and solution}

Equations (1) to (7), which describe the conjugated heat conduction in the base materials and fillers, are solved by software-FLUENT [35-38]. The cell is discretized by finite volume method.

The discretized equations are solved by central difference scheme. The calculation methodology can be summarized as following:

(1) Assume initial temperature values for both the fillers and the base materials.
Table 2. Time consumed in calculation with different mesh numbers for a cell with $9 \%$ randomly arranged I shaped cross-sectional fillers

\begin{tabular}{|l|c|c|c|}
\hline Mesh number & $\begin{array}{c}\text { Meshing time } \\
\text { [s] }\end{array}$ & $\begin{array}{c}\text { Calculation } \\
\text { time } \\
{[\mathbf{s}]}\end{array}$ & $\begin{array}{c}\text { Relative } \\
\text { thermal } \\
\text { conductivity }\end{array}$ \\
\hline $100 \times 100$ & 34 & 36 & 1.438 \\
\hline $200 \times 200$ & 80 & 82 & 1.458 \\
\hline $400 \times 400$ & 600 & 420 & 1.476 \\
\hline $800 \times 800$ & 5400 & 2100 & 1.478 \\
\hline
\end{tabular}

(2) Using the temperature values for fillers at interface as the boundary values for the base materials to solve Equation (1), one gets the temperature field of the base materials..

(3) Taking the just calculated base material temperatures at interface as the boundary values to solve Equation (2), one gets the temperature fields in the fillers.

(4) Return to step (2) until all the old values and new values for both the base materials and the fillers are converged. In this way, the heat conduction equations are satisfied.

To assure the accuracy of the results, a check of grid independence is conducted. For a sample with randomly arranged I shaped cross-sectional fillers. The size of the cell is $0.01 \mathrm{~m}$. The volumetric content of filler is $9 \%$. The calculated relative thermal conductivity and the time consumed in meshing and calculating are presented in Table 2. The time required to perform the analysis is greatly increased as the mesh refinement increases. However no obvious change is observed for the results when the grid size is more than $400 \times 400$. Grid independence test is done and numerical uncertainty is within $0.2 \%$. It indicates that grid size of $400 \times 400$ is adequate for this problem, because the difference between the results for grid size $800 \times 800$ and $400 \times 400$ is less than $0.15 \%$. A validated commercial software-FLUENT is used to design the shape of fillers and calculate the data in the analysis. High order scheme, low relaxation factor and re-meshing are used to prevent undergoing oscillation. When the average heat flux on the y direction are known, the thermal conductivity is calculated by Equation (7).

\section{Results and discussion}

\subsection{Effects of the prismatic filler arrangements}

To theoretically study the effects of the prismatic filler arrangements having various cross-sectional 
shapes on the thermal conductivity, temperature fields in the cell were calculated. The base materials studied here was paraffin wax, with thermal conductivity $0.36 \mathrm{~W} \cdot \mathrm{m}^{-1} \cdot \mathrm{K}^{-1}$. The filler material was steel with thermal conductivity of $50.2 \mathrm{~W} \cdot \mathrm{m}^{-1} \cdot \mathrm{K}^{-1}$. Using the selected materials, the thermal conductivity of composites was calculated by numerical analysis method using the model proposed in this study. The thermal conductivity of the investigated composite is measured by Hot Disk (DRX-2). It is based on the Transient Plane Source (TPS) technique, and can be widely used in the measurement of the thermal conductivity of materials.

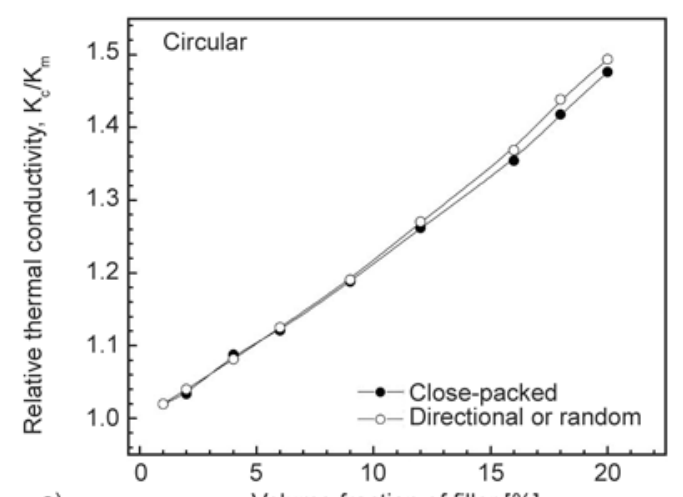

a)
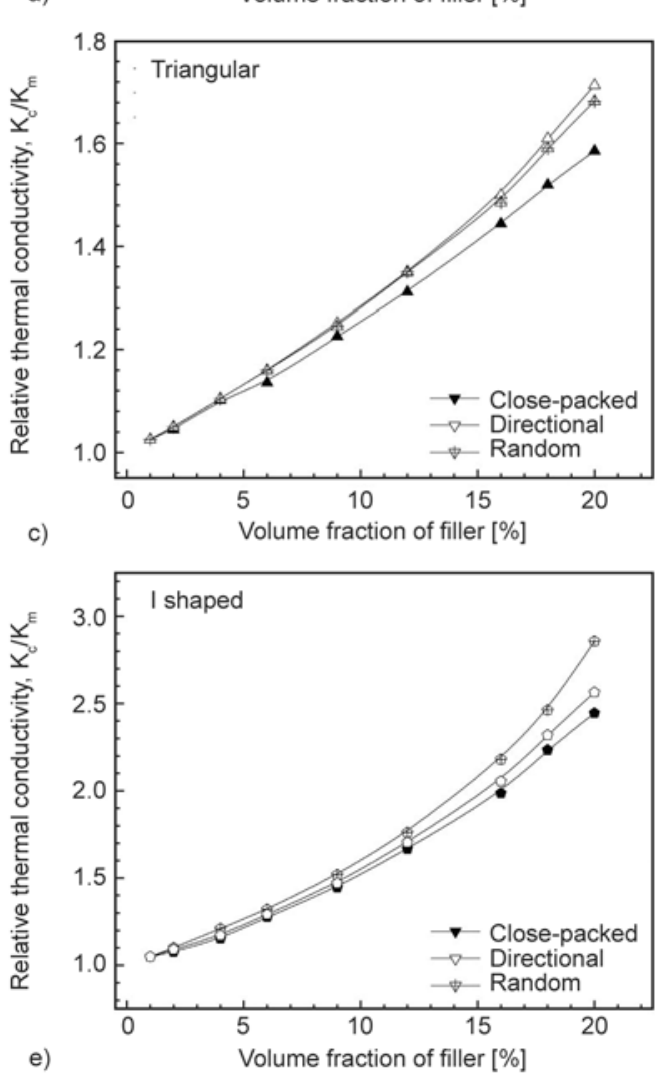

Figure 4 shows the relative thermal conductivity of composite materials for various filler arrangements at different filler contents. There are three typical filler arrangements and six representative filler crosssectional shapes. As seen, the thermal conductivity increases with filler content, regardless of the filler arrangements and cross-sectional shapes. In a directionally arranged cell, the fillers are arranged as that in Figure 2b. Their cross-sectional main axes are the same as the input heat flux direction, and the positions are randomly. In these cases, all the filler crosssectional shapes have the largest contribution for thermal conductivity improvement. On the contrary,
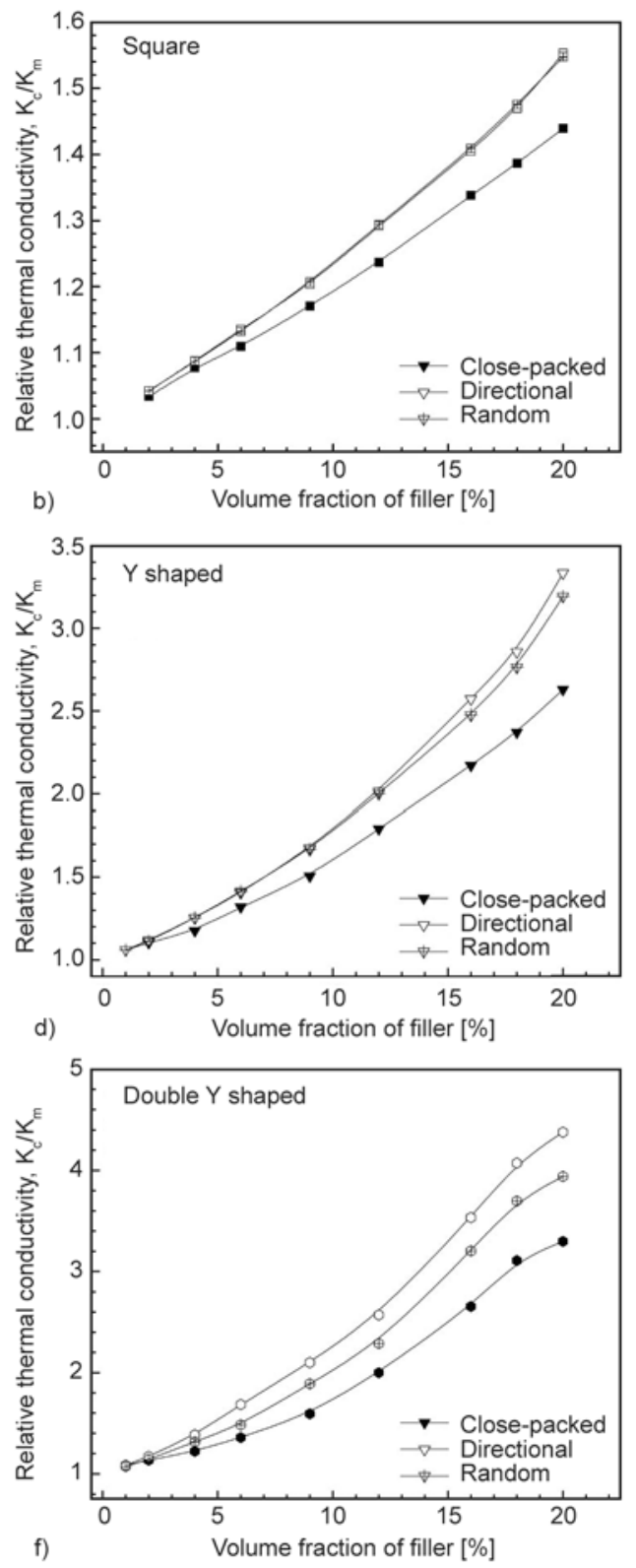

Figure 4. Relative thermal conductivity of composite materials with different filler arrangements and filler cross-sectional shapes: a) circular, b) square, c) triangular, d) Y shaped, e) I shaped, f) double Y shaped 
when the fillers are close-packed arranged in polymers as showed in Figure 2a, the contribution of all filler cross-sectional shapes are the smallest. Compared to directional and close-packed arrangements, the random arrangement has middle contribution to the thermal conductivity improvement.

The effects of the filler arrangements are complex for different filler cross-sectional shapes. The circular is a perfectly symmetrical shape. It is not affected by the orientation angle, so the directional and random arrangements have the same structure model. As seen from Figure 4 circular cross-sectional filler, at lower filler content below $10 \%$, the thermal conductivity of composites with randomly and closed-packed arranged fillers are basically identical. When the filler content larger than $10 \%$, the results of the randomly arranged case are larger than that of close-packed case. The differences increase with filler content. However, at a large filler content of $20 \%$, the maximize difference is less than $2 \%$. Some cross-sectional shapes are similar to symmet- rical structure, like square, triangular and $\mathrm{Y}$ shaped. They have similar heat conduction distance at different filler arrangements. Their thermal conductivities are insensitive to orientation angles. The thermal conductivities of composites with directionally and randomly arranged fillers have small difference as showed in Figure 4 for the square cross-sectional filler, triangular cross-sectional filler and $\mathrm{Y}$ shaped cross-sectional filler cases. Their values are small in close-packed arrangement. The control of orientation angles is not effective for these filler cross-sectional shapes. In order to avoid aggregate of fillers, the new technology should be investigated to mix well with base polymer. Other filler cross-sectional shapes like double Y shaped, I shaped, T shaped, elliptical, rhombic and rectangular, are more sensitive to filler arrangement. The heat conductivity distance decreases drastically with orientation angles. The differences of thermal conductivity between the directional and the random cell become more and more apparent with increasing filler content. At

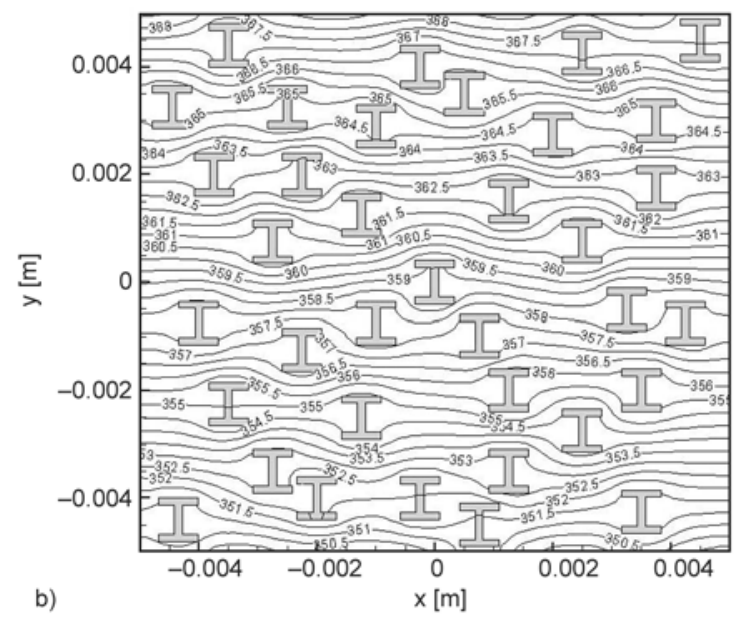

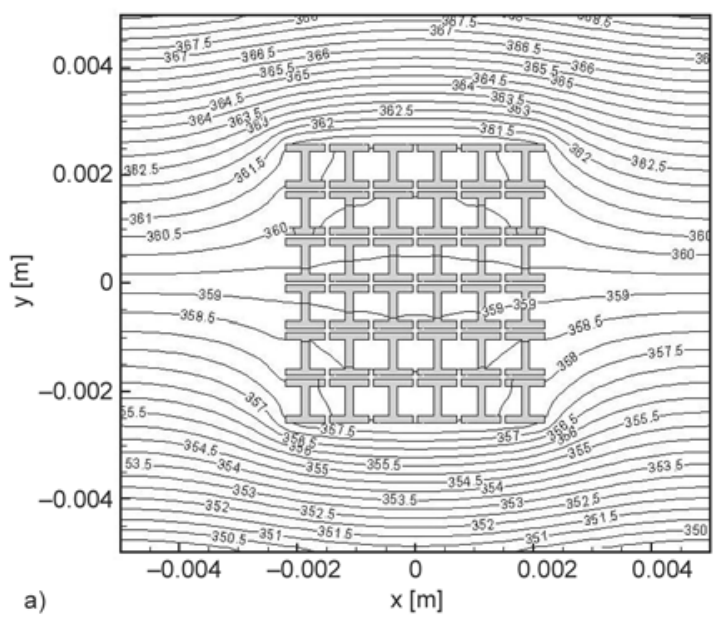

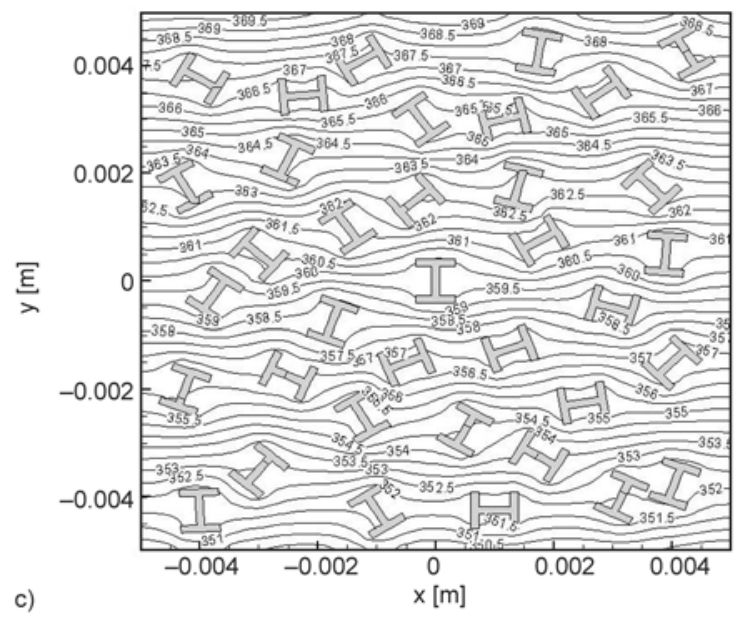

Figure 5. Contours of temperature $[\mathrm{K}]$ in the sample cell with $9 \%$ I shaped cross-sectional fillers. (a) close-packed arrangement, (b) directional arrangement, (c) random arrangement. 
the same filler content of $20 \%$, the differences of rectangular cross-sectional filler is $34 \%$, I shaped cross-sectional filler is $12.5 \%$. By contrast, the difference of the square cross-sectional filler is no more than $0.35 \%$. This shows that to make composite with directional arrangement of fillers is very important for most filler cross-sectional shapes excepting circular.

The effect of fillers augmentation can be explained by the isotherms in the unit cell. Figures 5 and 6 show the effects of the filler arrangements on the isotherms for two filler cross-sectional shapes: I shaped and square. The temperature fields in the base materials are deformed and shortcut by fillers. The fillers act as numerous bridges, transporting the heat fluxes through them. For each bridge, it receives heat at the high temperature side, and releases the heat at the low temperature side. The middle part of the filler is capable of transporting this received heat effectively, with little temperature gradients. The base material near the filler seldom takes part in

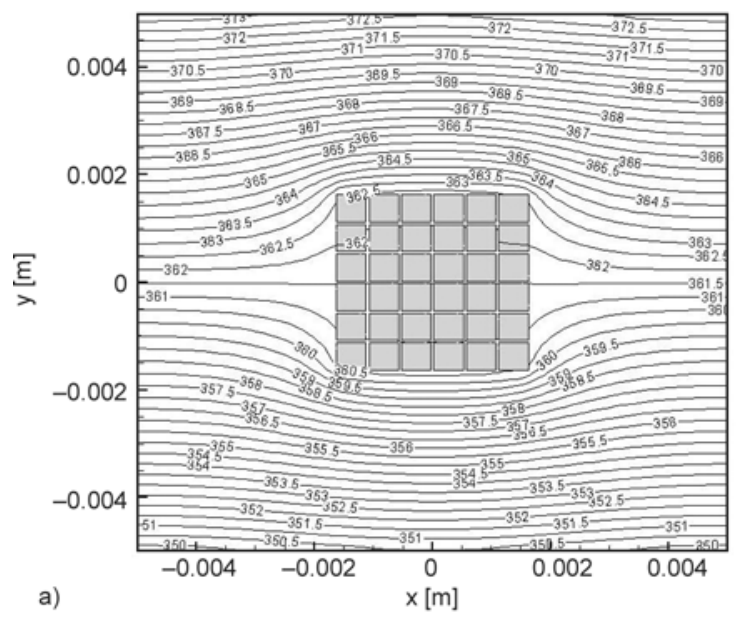

heat transport in the direction along the isotherms in the fillers, rather, it is shortcut. In this way, the heat transport is increased in the cell.

As seen from Figure 5a and Figure 6a, when the fillers in close-packed arrangement, all the fillers arranged in the central of polymer with small distance. This case is very similar to that the fillers are wired together to function as a single system, like a 'larger filler'. The larger filler is beneficial for heat conductivity increasing. The effect in temperature field deformation is more obvious than single filler. However, the larger filler is only one and distributed in the central of the cell. The role of the fillers to enhance heat transfer is very weak in most other regions. Thus, the improvement of heat conductivity is very limited in the close-packed arrangement. By comparing Figures $5 b, 5 c$ and Figures $6 b, 6 c$, it is found that when the filler arrangement changes from directional to random, the isotherms change slightly for square cross-sectional fillers. However, the change for I shaped cross-sectional filler is

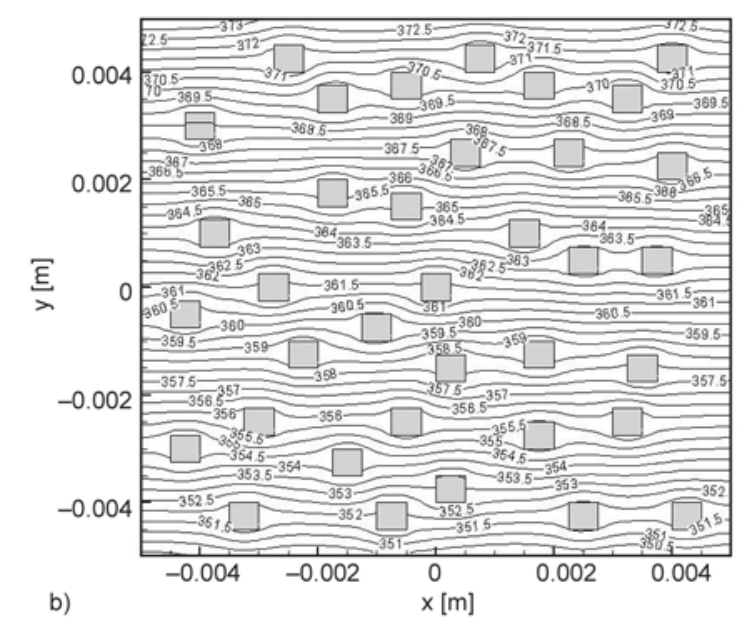

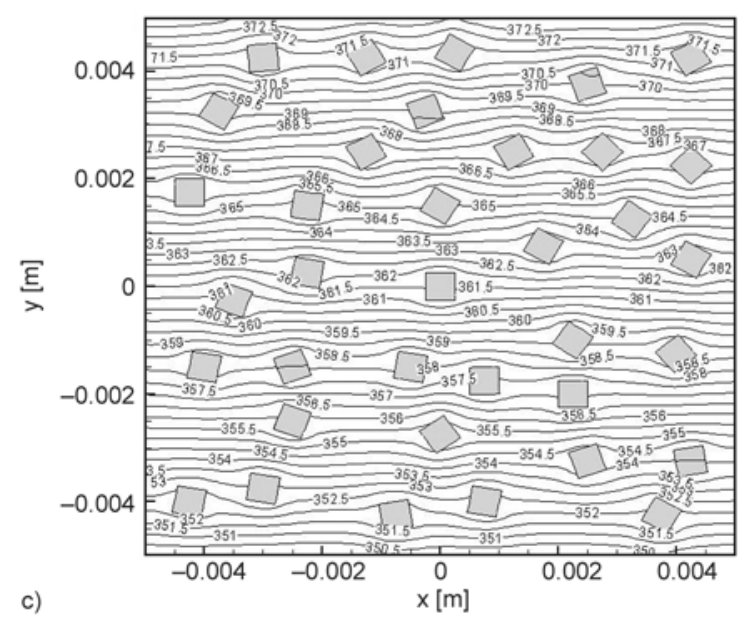

Figure 6. Contours of temperature $[\mathrm{K}]$ in the sample cell with $9 \%$ square cross-sectional fillers. (a) close-packed arrangement, (b) directional arrangement, (c) random arrangement. 
large. The bridge for heat conduction is shortened when I shaped cross-sectional filler is deflected. The thermal conductivity of composites with directionally arranged I shaped cross-sectional filler is much larger than random arrangement. The directional arrangement of I shaped cross-sectional filler is necessary to maximize the role of fillers.

\subsection{Effects of filler cross-sectional shapes}

All the proposed filler cross-sectional shapes listed in Table 1 are modeled. The arrangements of fillers have three types, as already indicated. The thermal conductivity of these composites is then calculated and compared for various filler cross-sectional shapes, as shown in Figures 7-9. The thermal conductivity increases with filler content in three filler arrangements, regardless of the filler cross-sectional shapes. However, the steps of increase are different. The double Y shaped cross-sectional filler resulting in a larger increasing rate, followed by the Y shaped cross-sectional filler. The trends of other filler cross-sectional shapes are dependent in filler arrangements. The order of thermal conductivity increasing for close-packed arranged fillers is showed in Figure 7, double Y shaped $>$ Y shaped $>$ I shaped $>$ T shaped $>$ rectangular $\approx$ elliptical $\approx$ rhombic $\approx$ triangular $\approx$ square $\approx$ circular. Except double Y shaped, Y shaped, I shaped and T shaped,

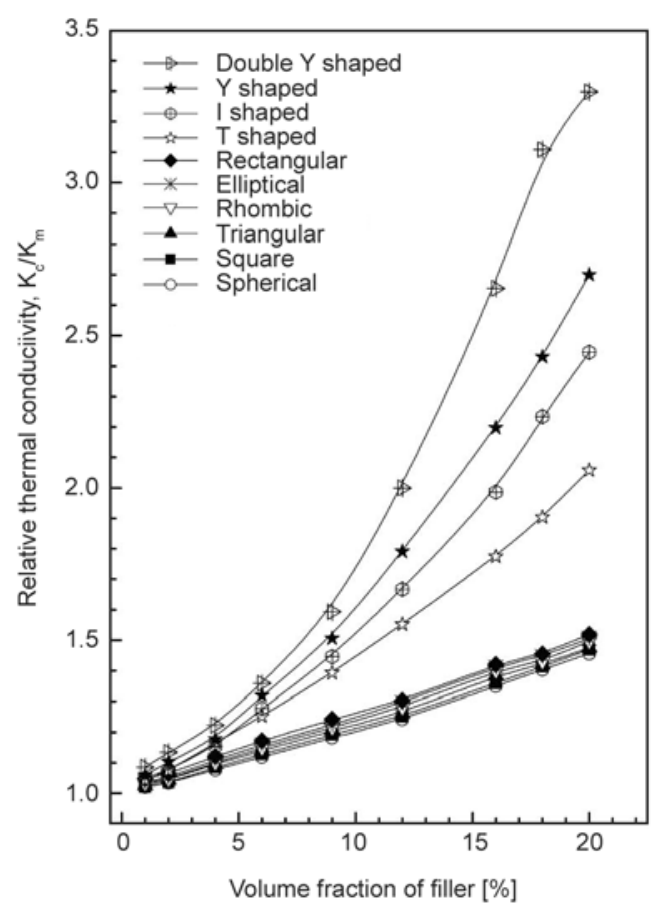

Figure 7. Relative thermal conductivity of composites materials with different filler cross-sectional shapes: close-packed arrangement the effects of filler cross-sectional shapes on thermal conductivity are not obvious in this filler arrangement. Generally, the fillers are easy to be attracted together due to their large specific surface area and high surface energy. The effects of most filler shapes will be seriously deteriorated in this situation. New technique of making composite, such as liquid phase method, should be designed to overcome this aggregation.

Figure 8 shows the thermal conductivity of composites with directionally arranged fillers. The order of thermal conductivity increasing is: double $\mathrm{Y}$ shaped $>\mathrm{Y}$ shaped $>$ rectangular $\approx$ shaped $>\mathrm{T}$ shaped $>$ elliptical $>$ rhombic $>$ triangular $>$ square $\approx$ circular. All the cross-sectional shapes with directionally arranged fillers have larger effects on increasing thermal conductivity. In industrial application, the technology of making composite with directional filler arrangement should be paid special attention. The trends for randomly arranged fillers are showed in Figure 9. The order of thermal conductivity increasing is: double $Y$ shaped $>Y$ shaped $>$ I shaped $>$ T shaped $>$ rectangular $>$ elliptical $>$ rhombic $\approx$ triangular $>$ square $\approx$ circular. For the random arrangement, the constructible filler cross-sectional shapes [39] such as double Y shaped, Y shaped, I shaped and $\mathrm{T}$ shaped are better than other regular shapes in enhancing thermal conductivity. They have long heat

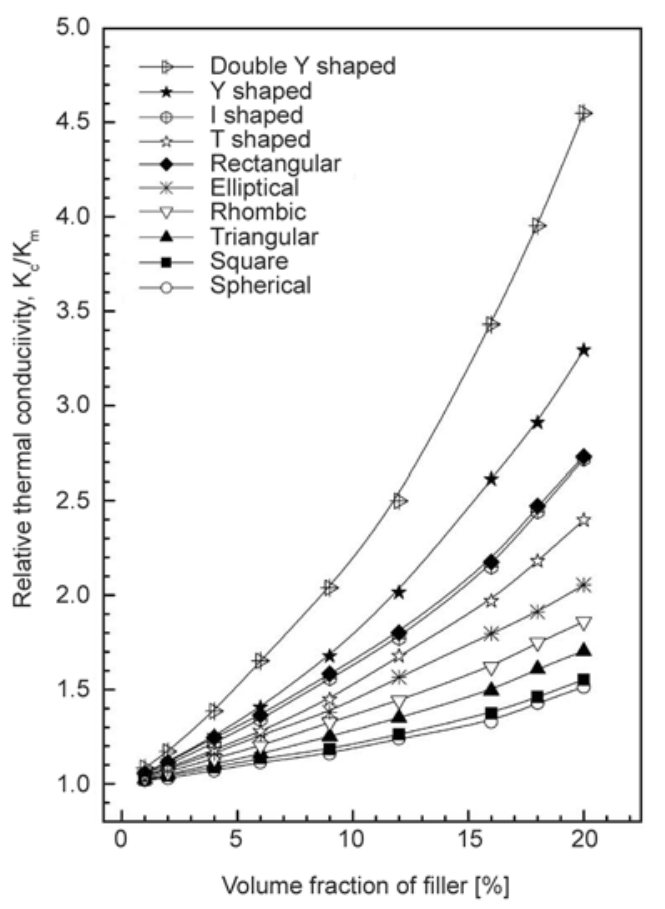

Figure 8. Relative thermal conductivity of composites materials with different filler cross-sectional shapes: directional arrangement 


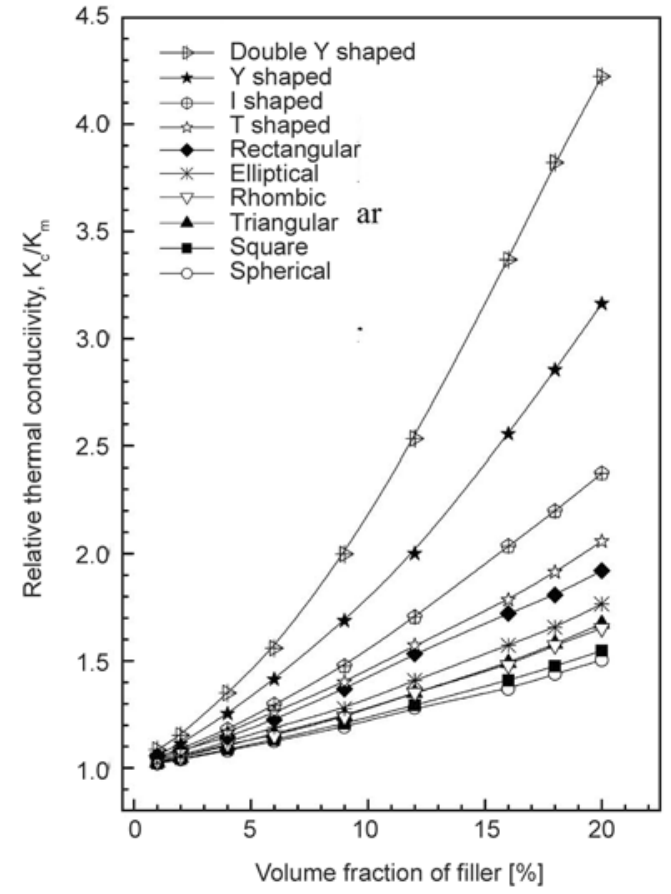

Figure 9. Relative thermal conductivity of composites materials with different filler cross-sectional shapes: random arrangement

conduction distances and large contact areas even when they are placed unfavorably. From above analysis, it can be concluded the best fillers are those that have long heat conduction distances, regardless of filler arrangement. The aggregation of fillers should be avoided for all the filler cross-sectional shapes.

Above-mentioned results show that the filler arrangement has very large effect on enhancement of thermal conductivity. In future study, the control of filler arrangement should be investigated for most filler shapes.

\section{Conclusions}

To add highly conductive fillers in the polymer matrix is an effective way to increase thermal conductivity of polymers. This study investigated the effects of three typical filler arrangements and ten filler cross-sectional shapes. Following results can be concluded:

(1) For increasing thermal conductivity, best filler arrangement is that all the fillers should have the longest heat conduction distances, and the largest sphere diameter of influence. From this respect, the directional arrangement for double Y shaped, I shaped, T shaped, elliptical, rhombic and rectangular cross-sectional fillers are the best. The efficiency of circular, square, triangular and $\mathrm{Y}$ shaped cross-sectional fillers are similar in directional and random arrangement. Thermal conductivity is the smallest in close-packed arrangement for all the filler cross-sectional shapes.

(2) Best filler shape should be constructible shape. Best fillers should have relatively long heat conduction distances in any types of the filler arrangements. The double Y shaped, Y shaped, I shaped and $\mathrm{T}$ shaped are the best cross-sectional shapes in increasing heat conductivity.

(3) In industrial applications, new methods to control the arrangement of fillers should be investigated, and the double Y shaped, Y shaped, I shaped and $\mathrm{T}$ shaped cross-sectional fillers should be used to replace the traditional fillers like spherical and fibroid fillers.

\section{Acknowledgements}

The Project is supported by Natural Science Foundation of China, No.51406072.

\section{Nomenclature}

$a_{1} \quad$ sectional length

AB left boundary of cell

AD top boundary of cell

$b_{1} \quad$ sectional length

BC bottom boundary of cell

$c_{\mathrm{p}} \quad$ specific heat $\left[\mathrm{kJ} \cdot \mathrm{kg}^{-1} \cdot \mathrm{K}^{-1}\right]$

$c_{1} \quad$ sectional length

$d_{1} \quad$ sectional length

DC right boundary of cell

$K \quad$ thermal conductivity $\left[\mathrm{W} \cdot \mathrm{m}^{-1} \cdot \mathrm{K}^{-1}\right.$ ]

$L_{\mathrm{x}} \quad$ length along the $x$ axis

$L_{\mathrm{y}} \quad$ height along the $y$ axis

$n \quad$ normal direction

$q \quad$ heat flux $\left[\mathrm{W} \cdot \mathrm{m}^{-2}\right]$

$V \quad$ volumetric fraction

$x, y$ coordinates $[\mathrm{m}]$

$x_{0} \quad$ coordinate of filler cross-sectional center [m]

$y_{0} \quad$ coordinate of filler cross-sectional center [m]

\section{Greek letters}

$\alpha \quad$ apex angle for triangle $\left[{ }^{\circ}\right]$

$\beta \quad$ apex angle for rhombus $\left[{ }^{\circ}\right]$

$\beta_{0} \quad$ orientation angle $\left[{ }^{\circ}\right]$

$\gamma \quad$ apex angle for $\mathrm{Y}$ and double $\mathrm{Y}\left[{ }^{\circ}\right]$

$\rho \quad$ density $\left[\mathrm{kg} / \mathrm{m}^{3}\right]$

\section{Subscripts}

$\begin{array}{ll}c & \text { composite } \\ f & \text { filler } \\ m & \text { polymer matrix }\end{array}$ 


\section{References}

[1] Zaheed L., Jachuck R. J. J.: Review of polymer compact heat exchangers, with special emphasis on a polymer film unit. Applied Thermal Engineering, 24, 2323 2358 (2004).

DOI: $10.1016 /$ j.applthermaleng.2004.03.018

[2] Zhang L-Z., Wang X-J., Quan Y-Y., Pei L-X.: Conjugate heat conduction in filled composite materials considering interactions between the filler and base materials. International Journal of Heat and Mass Transfer, 64, 735-742 (2013).

DOI: 10.1016/j.ijheatmasstransfer.2013.05.021

[3] Joen C. T., Park Y., Wang Q., Sommers A., Han X., Jacobi A.: A review on polymer heat exchangers for HVAC\&R applications. International Journal of Refrigeration, 32, 763-779 (2009).

DOI: $10.1016 /$ j.ijrefrig.2008.11.008

[4] Wang Q., Han X. H., Sommmers A., Park Y., T'Joen C., Jacobi A.: A review on application of carbonaceous materials and carbon matrix composites for heat exchangers and heat sinks. International Journal of Refrigeration, 35, 7-26 (2012).

DOI: 10.1016/j.ijrefrig.2011.09.001

[5] Liu X. H., Jiang Y.: Coupled heat and mass transfer characteristic in packed bed dehumidifier/regenerator using liquid desiccant. Energy Conversion and Management, 49, 1357-1366 (2008).

DOI: $10.1016 / \mathrm{j}$.enconman.2008.01.009

[6] Mahmud K., Mahmood G. I., Simonson C. J., Besant R. W.: Performance testing of a counter-cross-flow runaround membrane energy exchanger (RAMEE) system for HVAC applications. Energy and Buildings, 42, 1139-1147 (2010).

DOI: $10.1016 /$ j.enbuild.2010.02.005

[7] Vali A., Simonson C. J., Besant R. W.: Numerical model and effectiveness correlations for a run-around heat recovery system with combined counter and cross flow exchangers. International Journal of Heat and Mass Transfer, 52, 5827-5840 (2009).

DOI: 10.1016/j.ijheatmasstransfer.2009.07.020

[8] Zhang L-Z., Wang X-J., Pei L-X.: Nonlinear programming optimization of filler shapes for composite materials with inverse problem technique to maximize heat conductivity. International Journal of Heat and Mass Transfer, 55, 7287-7296 (2012).

DOI: 10.1016/j.ijheatmasstransfer.2012.07.059

[9] Han Z., Fina A.: Thermal conductivity of carbon nanotubes and their polymer nanocomposites: A review. Progress in Polymer Science, 36, 914-944 (2011). DOI: $10.1016 /$ j.progpolymsci.2010.11.004

[10] Sofian N. M., Rusu M., Neagu R., Neagu E.: Metal powder-filled polyethylene composites. V. Thermal properties. Journal of Thermoplastic Composite Materials, 14, 20-33 (2001).

DOI: 10.1106/9N6K-VKH1-MHYX-FBC4
[11] Yu A., Ramesh P., Sun X., Bekyarova E., Itkis M. E., Haddon R. C.: Enhanced thermal conductivity in a hybrid graphite nanoplatelet - Carbon nanotube filler for epoxy composites. Advanced Materials, 20, 47404744 (2008). DOI: $10.1002 / \mathrm{adma} .200800401$

[12] Lewis T. B., Nielsen L. E.: Dynamic mechanical properties of particulate-filled composites. Journal of Applied Polymer Science, 14, 1449-1471 (1970).

DOI: $10.1002 / a p p .1970 .070140604$

[13] Nozad I., Garbonell R. G., Whitaker S.: Heat conduction in multiphase systems - I: Theory and experiment for two-phase systems. Chemical Engineering Science, 40, 843-855 (1985).

DOI: 10.1016/0009-2509(85)85037-5

[14] Whitaker S.: The method of volume averaging (theory and applications of transport in porous media). Springer, Haifa (1998).

[15] Nielsen L.: The thermal and electrical conductivity of two-phase systems. Industrial and Engineering Chemistry Fundamentals, 13, 17-20 (1974).

DOI: $10.1021 / \mathrm{i} 160049 \mathrm{a} 004$

[16] Baschirow A. B., Manukian A. M.: Thermal conductivities of polymers at various temperatures and pressures. Polymer Mechanics, 3, 564-566 (1974). DOI: $10.1007 / \mathrm{BF} 00865620$

[17] Bruggeman D. A.: Dielectric constant and conductivity of mixtures of isotropic materials. Annals of Physics, 24, 636-679 (1953).

[18] Agari Y., Uno T.: Estimation on thermal conductivities of filled polymers. Journal of Applied Polymer Science, 32, 5705-5712 (1986).

DOI: 10.1002/app.1986.070320702

[19] Agari Y., Ueda A., Nagai S.: Thermal conductivity of a polyethylene filled with disoriented short-cut carbon fibers. Journal of Applied Polymer Science, 43, 11171124 (1991).

DOI: 10.1002/app.1991.070430612

[20] Agari Y., Ueda A., Nagai S.: Thermal conductivities of composites in several types of dispersion systems. Journal of Applied Polymer Science, 42, 1665-1669 (1994).

DOI: 10.1002/app.1991.070420621

[21] Tavman I. H., Akinci H.: Transverse thermal conductivity of fiber reinforced polymer composites. International Communications in Heat and Mass Transfer, 27, 253-261 (2000).

DOI: $10.1016 / \mathrm{S} 0735-1933(00) 00106-8$

[22] Halpin J. C.: Stiffness and expansion estimates for oriented short fiber composites. Journal of Composite Materials, 3, 732-734 (1969). DOI: $10.1177 / 002199836900300419$

[23] Sanada K., Tada Y., Shindo Y.: Thermal conductivity of polymer composites with close-packed structure of nano and micro fillers. Composites Part A: Applied Science and Manufacturing, 40, 724-730 (2009).

DOI: 10.1016/j.compositesa.2009.02.024 
[24] Yang S-Y., Lin W-N., Huang Y-L., Tien H-W., Wang JY., Ma C-C. M., Li S-M., Wang Y-S.: Synergetic effects of grapheme platelets and carbon nanotubes on the mechanical and thermal properties of epoxy composites. Carbon, 49, 793-803 (2011).

DOI: $10.1016 /$ j.carbon.2010.10.014

[25] Fricke H.: A mathematical treatment of the electric conductivity and capacity of disperse systems I. The electric conductivity of a suspension of homogeneous spheroids. Physical Review Letters, 24, 575-587 (1924). DOI: $10.1103 /$ PhysRev.24.575

[26] Nan C-W., Birringer R., Clarke D. R., Gleiter H.: Effective thermal conductivity of particulate composites with interfacial thermal resistance. Journal of Applied Physics, 81, 6692-6699 (1997).

DOI: $10.1063 / 1.365209$

[27] Duan H. L., Karihaloo B. L.: Effective thermal conductivities of heterogeneous media containing multiple imperfectly bonded inclusions. Physical Review B, 75, 064206/1-064206/9 (2007).

DOI: $10.1103 /$ PhysRevB.75.064206

[28] Wang X-J., Zhang L-Z., Pei L-X.: Thermal conductivity augmentation of composite polymer materials with artificially controlled filler shapes. Journal of Applied Polymer Science, 131, 39550/1-39550/10 (2014).

DOI: 10.1002/app.39550

[29] Yang B., Han Z. H.: Temperature-dependent thermal conductivity of nanorod-based nanofluids. Applied Physical Letters, 89, 083111/1-083111/3 (2006). DOI: $10.1063 / 1.2338424$

[30] Casado U., Marcovich N. E., Aranguren M. I., Mosiewicki M. A.: High-strength composites based on tung oil polyurethane and wood flour: Effect of the filler concentration on the mechanical properties. Polymer and Engineering and Science, 49, 713-721 (2009). DOI: $10.1002 /$ pen.21315

[31] Han Y., Lv S., Hao C., Ding F., Zhang Y.: Thermal conductivity enhancement of $\mathrm{BN} /$ silicone composites cured under electric field: Stacking of shape, thermal conductivity, and particle packing structure anisotropies. Thermochimica Acta, 259, 68-73 (2012). DOI: $10.1016 /$ j.tca.2011.11.029
[32] Xu Y., Yagi K.: Automatic FEM model generation for evaluating thermal conductivity of composite with random materials arrangement. Computational Materials Science, 30, 242-250 (2004).

DOI: $10.1016 /$ j.commatsci.2004.03.011

[33] Huang S-M., Zhang L-Z., Tang K., Pei L-X.: Fluid flow and heat mass transfer in membrane parallelplates channels used for liquid desiccant air dehumidification. International Journal of Heat and Mass Transfer, 55, 2571-2580 (2012).

DOI: 10.1016/j.ijheatmasstransfer.2012.01.003

[34] Phelan P. E., Niemann R. C.: Effective thermal conductivity of a thin, randomly oriented composite material. Journal of Heat Transfer, 120, 971-976 (1998). DOI: $10.1115 / 1.2825917$

[35] Liu X. H., Jiang Y., Qu K. Y.: Heat and mass transfer model of cross flow liquid desiccant air dehumidifier/ regenerator. Energy Conversion and Management, 48, 546-554 (2007).

DOI: $10.1016 /$ j.enconman.2006.06.002

[36] Zhang L-Z., Huang S-M.: Coupled heat and mass transfer in a counter flow hollow fiber membrane module for air humidification. International Journal of Heat and Mass Transfer, 54, 1055-1063 (2011). DOI: 10.1016/j.ijheatmasstransfer.2010.11.025

[37] Zhang L-Z., Huang S-M., Zhang W-B.: Turbulent heat and mass transfer across a hollow fiber membrane bundle considering interactions between neighboring fibers. International Journal of Heat and Mass Transfer, 64, 162-172 (2013).

DOI: 10.1016/j.ijheatmasstransfer.2013.04.035

[38] Huang S. M., Yang M. L.: Longitudinal fluid flow and heat transfer between an elliptical hollow fiber membrane tube bank used for air humidification. Applied Energy, 112, 75-82 (2013).

DOI: 10.1016/j.apenergy.2013.05.080

[39] Devpura A., Phelan P. E., Prasher R. S.: Size effects on the thermal conductivity of polymers laden with highly conductive filler particles. Microscale Thermophysical Engineering, 5, 177-189 (2001). DOI: $10.1080 / 108939501753222869$ 